\title{
Death Anxiety, PTSD, Trauma, Grief, and Mental Health of Palestinians Victims of War on Gaza
}

\author{
Thabet $\mathrm{AA}^{1 *}$, Tawahina $\mathrm{AA}^{2}$, Sarraj $\mathrm{EE}^{3}$ and Vostanis $\mathrm{P}^{4}$ \\ ${ }^{1}$ Al Quds University, School of Public Health, Child Institute-Gaza PO Box 5314, Israel \\ ${ }^{2}$ Clinical Psychologist, Gaza Community Mental Health Programme, Israel \\ ${ }^{3}$ Psychiatrist, Gaza Community Mental Health Programme, Israel \\ ${ }^{4}$ School of Medicine- Greenwood Institute of Child Health, School of Psychology Westcotes House, Westcotes Drive, Leicester LE3 OQU, UK
}

\begin{abstract}
Purpose: Exposure to war trauma has been independently associated with posttraumatic stress (PTSD) and grief in children and adults. The aim of this study was to establish the relationship between war traumatic experiences due to last war on Gaza, PTSD, traumatic grief, death anxiety, and general mental health.

Methods: The study was conducted in the Gaza Strip; in areas exposed to war for 23 days. The sample included 374 adults aged from 22 to 65 years with mean age 40.13. Participants completed measures of experience of traumatic events (Gaza Traumatic Checklist-War on Gaza), PTSD, Grief inventory, Arabic Version of Death Anxiety Scale, and
\end{abstract} GHQ-28.

Results: Palestinians experiences variety of traumatic events: The most common reported traumatic events were: $95.7 \%$ said they hear of shelling and bombardment of the their area, $94.7 \%$ reported watching mutilated bodies in TV, $92.8 \%$ reported seeing the bombardment effects on ground, $71.7 \%$ said they had lack of water, food and electricity during the war, and $72.2 \%$ said they moved to save place during the war. Each person reported 13.80 traumatic events. The results showed that no one felt safe at home, $2.1 \%$ of fathers said they were able to protect their children, while $2.8 \%$ of mothers said they were safe at homes. The study showed that $3.1 \%$ fathers were able to protect their children compared to $6.6 \%$ of mothers, $2.8 \%$ of fathers were able to protect themselves compared to $6.1 \%$ of mothers, and $3.1 \%$ of fathers said that someone outside the home were able to protect him compared to $2.8 \%$ of mothers.

The study showed that 71 persons lost someone from their family included extended family which represented 18.8 $\%$ of the participants and 303 did not loss anyone (81.2\%) from their families (first, second, third relatives) during the war compared.

The study showed that mean grief reaction was $11.52(S D=4.82)$. The study showed that mean grief reactions reported by male were 10.1 and mean in female was 12.69 . There were statistically significant differences toward females in grief reactions.

Using scoring of DSM-IV of one intrusion symptom, three avoidance, and two arousal symptoms, 248 people rated as PTSD which represented $66.6 \%$ of the sample and 125 persons reported no PTSD (35.5\%). The results showed that PTSD was reported more in females compared to males. The results showed that mean death anxiety in males was 37.4 compared to female mean $=44.9$. There were statistically significant differences toward females.

The study showed than mean GHQ-28 was 15.6 , somatization mean was 4.3 , anxiety mean was 5 , social dysfunction mean was 3.2, and depression mean was 3.2. Using the previous cutoff point of the GHQ-28 (4/5), the result showed that $90.9 \%$ were rated as cases and need further investigation, while $9.1 \%$ were not cases.

Conclusions: This study revealed each person reported 13.80 traumatic events. The results showed that no one felt safe at home. The study showed that 71 persons lost someone from their family included extended family which resulted in grief reaction where females reported more grief reactions. PTSD rate was $66.6 \%$ of the sample PTSD was reported more in females compared to males. Those victims had to be evaluated and treated as soon as the war finished and not leaving them to develop pathological grief and other mental health problems such as depression. Training programs must be created for people living in area of war and conflict including community sessions to increase their awareness about the impact of war on their psychosocial health and ways of coping with such problems in similar situation. Also, new intervention programs must be established for bereaved people using individual psychotherapy, psychoeducation, group crisis intervention, and community based intervention.

International organizations and national organization must work during war to protect civilian people from the atrocities of the war and provided a safe place for people and their children.

Keywords: War on gaza; Trauma; Traumatic grief; Adults; Death anxiety; PTSD; GHQ-28

\section{Introduction}

Palestinian families, like families in other societies, are subject to all forms of natural and man-made disasters and traumatic events. Review of the literature on the relationship between psychological disorders and exposure to political and military violence showed that anxiety, psychosomatic, and depression symptoms seem to be shared by most families who were subjected to political or military violence irrespective of their ethnic or cultural background.
*Corresponding author: Abdel Aziz Mousa Thabet, MD, PhD, Professor of Child and Adolescent Psychiatry, Al Quds University, School of Public Health, Child Institute-Gaza PO Box 5314, Israel, Tel: 0599604400; Fax: 2644210; E-mail: abdelazizt@hotmail.com

Received November 30, 2013; Accepted December 24, 2013; Published December 26, 2013

Citation: Thabet AA, Tawahina AA, Sarraj EE, Vostanis P (2013) Death Anxiety, PTSD, Trauma, Grief, and Mental Health of Palestinians Victims of War on Gaza. Health Care Current Reviews 1: 112. doi: 10.4172/2375-4273.1000112

Copyright: (C) 2013 Thabet AA, et al. This is an open-access article distributed under the terms of the Creative Commons Attribution License, which permits unrestricted use, distribution, and reproduction in any medium, provided the original author and source are credited. 
There is ample evidence that traumatic events of war and military violence are associated with PTSD and depressive symptoms. An examination of large, fairly representative samples of men and women age 16 or older living in Algeria, Cambodia, Ethiopia, and Gaza, de Jong et al. [1] found high rates of PTSD in each sample (37.4\%, 28.4\%, 15.8\%, and $17.8 \%$, respectively). In Algeria and Cambodia, and consistent with findings in the United States, women had higher rates of PTSD than did men (43.8\% versus $32.2 \%$ and $34.2 \%$ versus $20.6 \%$, respectively). In contrast, in Ethiopia and Gaza, women possessed similar or lower rates of PTSD in comparison with men (15.2\% versus $16.6 \%$ and $13.5 \%$ versus $22.6 \%$, respectively). In a representative sample of Kosovar Albanians age 15 or older assessed approximately one year after the end of the 1998-1999 war in Kosovo, Cardozo et al. [2] observed a PTSD prevalence rate of $25 \%$, compared with the rate of $17 \%$ that was found immediately following the war [3]. Similarly, immediately following the siege of Sarajevo, Rosner et al. [4] investigated the prevalence of current PTSD three years after the siege of Sarajevo. They found $18 \%$ in their group of residents, $32.7 \%$ in their group seeking medical treatment and $38.6 \%$ in their group seeking psychological treatment.

Thabet et al. [5] in study of 200 families from North Gaza and East Gaza who had exposed to continuous shelling in 2006, the results showed that parents reported a mean number of 8.5 traumatic events, $60 \%$ of parents had symptoms of potential clinical significance. Of PTSD, and $26.0 \%$ reported severe to very severe anxiety symptoms.

Siege was one of the new measures against the Palestinians in the Gaza Strip in which borders were closed and only few basic needs were allowed to enter through the gates between Israel and Gaza, while Rafah entrance to Egypt was closed most the time and only was open in irregular bases for humanitarian cases. Few studies were carried out to investigate the effect of siege on Palestinians well-being. Thabet et al. [6] in a study aimed to investigate impact of siege on Palestinians live in Gaza Strip and quality of life. A random sample of 386 subjects was selected from the entire Gaza Strip. The age ranged from 18 to 64 years with mean age was 41.53 years. The results showed that impact of siege items were: prices are sharply increased (97.67\%), I feel I am in a big prison $(92.23 \%)$, I cannot find things I need in the market (91.70\%), I quitted some purchased daily needs (88.30\%), and social visits are less than before (85.23\%). No statistically significant sex, place of residence, marital status differences in mean impact of siege. The results showed that only $11.8 \%$ of Palestinians were satisfied with their general health and only $8 \%$ said that they enjoy their life. Out of them, 38.9\% were satisfied with their personal relationships, $30.91 \%$ had negative feelings, such as blue mood, despair, anxiety, depression, $30.5 \%$ satisfied with their spirituality, religion and personal beliefs, $29.09 \%$ satisfied with their bodily appearance, and $26.5 \%$ had pain and discomfort. The results showed that quality of life scores mean was 64.19 , psychical domain mean was 18.37 , psychological domain mean was 17.67 , social domain mean was 8.71 , and environmental domain mean was 19.47. Males scored more in social domain. The results showed no statistically significant sex differences in mean quality of life, physical, psychological, and environmental domain. However, there was statistically significantly difference toward males in social domain. The results showed no statistically significant between refugee and citizens, place of residence, and marital status in mean quality of life (refugee vs. citizen) physical, psychological, social domain, and environmental domain. The results showed that there were statistically significant negative correlation between total siege scores and quality of life in which people that scored more in siege items had less total quality of life, physical domain, psychological domain, social domain, and environmental domain. The following items of impact of siege were predicated bad QOL suffering of being not able to receive proper medical care, cannot find some of the necessary things for my children (Milk, napkins, etc), feel in a big prison, went to Zakat organizations and other organizations to get the food, and started doing the papers for immigration.

Using the same previous data collected for the first study Thabet et al. [7], tried was to investigate the impact of siege of the Gaza Strip on Palestinians feelings of anger and anger state in relation psychological symptoms in relation to other socioeconomic variables. The sample of include 386 adults who interviewed using BSI. The results showed that the psychological symptoms ranged from 4 to 186 symptoms (mean=81.19), somatization $($ mean $=10.88)$, obsessive compulsive symptoms (mean=11.30), interpersonal sensitivity (mean=4.89), depression $($ mean $=8.62)$, anxiety $($ mean $=10.00)$, hostility $($ mean $=7.31)$, phobic anxiety (mean $=7.53$ ), paranoid $($ mean $=7.16$ ), and psychosis (mean=6.90). The results showed females reported more somatization, obsessive compulsive disorder, and phobic anxiety. Palestinians live in camps reported more general psychological problems, somatization, obsessive compulsive problems, interpersonal sensitivity, depression symptoms, anxiety, hostility, phobic anxiety, paranoid ideation than those in cities and village. However, psychosis symptoms were more common in people live in villages than in camps cities and. The results showed that there were statistically significant positive correlation between total siege scores and BSI in which people who scored more in siege items had more psychopathology, somatization, obsessive compulsive, interpersonal sensitivity, depression, anxiety, hostility, panic (phobic anxiety), paranoid ideation, and psychosis. The study showed that the most common anger state were: I feel upset (18.4\%) and I barely burned from the inside (10.4\%). While trait of anger items were: I feel upset when my work is not appreciated (21.1\%), I became angry when I did a good job and get the estimate is weak (19.9\%), and I am angry when mistakes of others delayed my work (16.1\%). The results showed no statistically significant sex, citizenship, relation to place of residence, and marital status differences in mean anger state and anger trait.

Thabet et al. [8] in a study aimed to investigate the effect of political violence on Palestinians in the Gaza Strip. The study population included 420 adult Palestinians living in the Gaza Strip. The data was collected during August 2006.The study showed that the most common traumatic events were, watching mutilated bodies and wounded people on TV (97.1\%), hearing the sonic sounds of the jetfighters (94.7\%), and witnessing the signs of shelling on the ground (93.2\%). Participants reported a mean number of 7.7 traumatic events. Participants reported different reactions to traumatic events, the most common reactions being: upset by reminders (62.7\%), distressing dreams (59.8\%), and amnesia (50.2\%). Mean PTSD items were 50.45, intrusion mean=17.1, avoidance mean $=18.9$, and arousal mean $=14.5$. Considering a cutoff score of 50 or more on the PTSD scale, 222 parents $(54.4 \%)$ had symptoms of potential clinical significance of PTSD. The result showed that there were no statistically significant differences in total PTSD scores, intrusion, avoidance, and hyperarousal and sex. Subjects mean Taylor anxiety scale was 28.05 . Following the cut-off point of 33 and more as severe to very severe anxiety, $26.5 \%$ of subjects scored as severe to very severe anxiety. The result showed that there were no statistically significant differences in total anxiety scores and sex, number of sibling, place of residence, and family monthly income of participants.

On $27^{\text {th }}$ December 2008 a new chapter of the conflict started to 
be written in which a new wave of violence erupted with at least 1340 Palestinians were killed and 5500 were injured in the Gaza Strip. This war on Gaza continued for 23 days.

Death distress, or a negative attitude toward death, is associated with different emotional states, mainly anxiety and fear. The academic research literature on death-related topics is dominated by studies purporting to investigate death anxiety [9]. Similarly, among 75 Kuwaiti college students, a general high-loaded factor of death distress included death anxiety, death depression, and death obsession [10]. Abdel-Khalek and Abdulla [11] in study of Palestinians in the West Bank found that women had higher mean scores than their men counterparts in death obsession, which was congruent with previous investigations on Kuwaiti and Lebanese participants, but contradicted the non-significant gender differences on the death obsession among Egyptian [12], Syrian [13], American [14], samples. However, in the Palestinian sample, it is possible that women, especially if they are mothers, may experience a heightened level of death obsession for their children than men do. Heightened death concerns among women have been reported by the majority of researchers who have examined gender differences. A widely cited early review by Polack [15] concluded that most previous studies reported gender differences, with women consistently reporting greater death anxiety than men. In his commentary on death concern, Kastenbaum [16] found the gender effect so consistent that, "In lieu of impressive data to the contrary, it seems reasonable to conclude that the higher self reported death anxiety for women is a robust finding". Moreover, results from Irish and Canadian students suggest that the effect generalizes beyond American culture [17].

The aim of this study is to investigate the psychological reactions in relation to loss, grief, and death anxiety in Palestinians victims of War in Gaza Strip.

\section{Methods}

\section{Setting and sample}

The Gaza Strip is a narrow elongated piece of land, bordering the Mediterranean Sea between Israel and Egypt, and covers $360 \mathrm{~km}^{2}$. It has high population density. About $17 \%$ of the population lives in the north of the Gaza Strip, 51\% in the middle, and 32\% in the south area. There is high unemployment, socioeconomic deprivation, family overcrowding, and short life expectancy. Nearly two-thirds of the population is refugees, with approximately $55 \%$ living in eight crowded refugee camps. The remainder lives in villages and towns. Since September 2005, the population of the Gaza Strip has been exposed to regular incursions and shelling, resulting in at least 200 deaths and many more injuries, in the last six months alone.

The study population included 374 participants living in areas exposed to 23 days of shelling, incursion, and bombardment, in the entire Gaza Strip. Families were selected randomly from the five areas of the Gaza Strip. One street was selected in each area, and every other household that fulfilled the family selection criteria. In larger buildings, one flat from each floor was selected.

The data collection was carried out by 8 trained professionals, under the supervision of the first author. The data was collected during Feb 2008. Families were interviewed in their homes. One of the difficulties of this study was that, throughout the interviews, there were strong feelings of hostility, anger, and intolerance to interview in the selected areas, for which reason the interviews had to be discontinued and repeated later.

\section{Measures}

Demographic questionnaire: Demographic information about the participants was obtained using a survey developed by the authors. This questionnaire includes sex, age, number of children, and education level.

War on Gaza Traumatic Events Checklist was used, describing the most common traumatic experiences families could have faced in the Gaza Strip during the last war on Gaza, including shelling of their area of residence, internal displacement. The checklist was revised from a version used in earlier research, adapted for the nature of traumatic events occurring during the current period. The participants answer with Yes (1) and no (0). The scoring of the scale is considered by summing all the answers. The internal consistency of the scale calculated using Cronbach's alpha, was $\alpha=0.88$ and split half was 0.79 .

The Posttraumatic Stress Disorder Checklist contains 17 items adapted from the DSM-IV PTSD symptom criteria. The 17 PTSD symptoms are rated by the participant for the previous month on a scale indicating the degree to which the respondent had been bothered by a particular symptom from 1 (not at all) to 5 (extremely). Items can be categorized as follows: items 1-4, 17: criteria B (intrusive reexperiencing); items 5-11: criteria $C$ (avoidance and numbness); and items 12-16: criteria $\mathrm{D}$ (hyperarousal). Respondents are asked to rate on a 5 -point Likert scale ( $1=$ not at all to $5=$ extremely) the extent to which symptoms troubled them in the previous month. Using the recommended PCL cutoff score of 50, Blanchard found cut of point of 44 . Previous research has suggested using as a minimum sum either a score of 3 or 4 on a symptom for it to count as positive towards the diagnosis. This scale was used in previous studies in the area and shoed high reliability and validity.

Maternal mental health: Ratings based on the General Health Questionnaire (GHQ-28). It covers severe depression and suicidal risk, anxiety and insomnia, social dysfunction, and somatic symptoms (59). Emphasis is on changes in condition, so items compare the present mental state to the person's normal mental health status. GHQ-28 scores above the cutoff of 4/5 are considered to be possible psychiatric 'cases. In a previous study, Cronbach's alpha was 0.91 and test-retest coefficient after six months was 0.90. Validation of GHQ28 as determined by comparison with the Clinical Interview Schedule yielded a sensitivity of 88.0 percent and specificity of 84.2 percent. This scale had been validated in Arabic culture and showed reliability and validity [7]. The internal consistency of the scale calculated using Cronbach's alpha, was $\alpha=0.91$ and split half was 0.88 .

Grief Screening Scale (GSS) Layne, Steinberg, Savjak, \& Pynoos, 1998): The GSS is a 10- item self-report screening inventory of grief symptoms in adolescents and adults. The scale is a revised version of The UCLA Grief Inventory and is composed to two factor-analytically derived subscales containing five items each: One subscale measures symptoms of normal grief, and the other measures symptoms of complicated grief. Symptoms experienced during the past 4 weeks are measures on a 5 point Likert-type frequency scale consisting of $0=$ never, $1=$ rarely, $2=$ sometimes, $3=$ often, $4=$ almost always. It was reported a full-scale Cronbach's alpha of .86 and good convergent validity. The internal consistency of the scale calculated using Cronbach's alpha, was $\alpha=0.69$ and split half was 0.68 .

The Arabic Scale of Death Anxiety (ASDA): The Arabic Scale of Death Anxiety (ASDA) [10]; consists of 20 statements. Each item is 
Citation: Thabet AA, Tawahina AA, Sarraj EE, Vostanis P (2013) Death Anxiety, PTSD, Trauma, Grief, and Mental Health of Palestinians Victims of War on Gaza. Health Care Current Reviews 1: 112. doi: 10.4172/2375-4273.1000112

answered on a 5 -point intensity scale anchored by 1 (no) and 5 (very much). Alpha reliabilities ranged from .88 to .93 , and item-remainder correlations ranged between .27 and .74 ; the 1-week test-retest reliability was .90 , denoting high internal consistency and temporal stability. The total score can range from 20 to 100, and a high score denotes high death anxiety. Among college students from Egypt, Kuwait, and Syria, alpha reliabilities ranged from .88 to .93 , and the one-week test-retest reliability was .90 , denoting high internal consistency and temporal stability. The correlations between the ASDA and Death Anxiety Scale ranged between .60 and .74 , denoting high convergent validity. The internal consistency of the scale calculated using Cronbach's alpha, was $\alpha=0.93$ and split half was 0.87 .

Statistical analysis: All data were analyzed using SPSS 14.0 statistical software. Frequency, mean, and standard deviation were used to describe the demographic data. We used t-tests to compare the differences of all variables between two groups and the PTSD, death anxiety, anxiety, and depression. A $P$ value less than 0.05 was considered statistically significant.

\section{Results}

Sociodemographic characteristics of study population $(\mathrm{N}=374)$. The sample consisted of 374 subjects, 193 were males (51.6\%) and 181 were females $48.4 \%$. The age ranged from 22 to 65 years with mean age 40.13 ( $\mathrm{SD}=8.8$ ). According to place of residence, $34.2 \%$ were from North Gaza, $24.9 \%$ were from Gaza city, $15.8 \%$ were from middle area, $7.8 \%$ from Khan Younis, and $17.4 \%$ were from Rafah area. According to type of living, $44 \%$ live in cities, $20.9 \%$ live in villages, and $34.8 \%$ live in refugee camps. According to family monthly income, $60.9 \%$ had less than 300 US \$ monthly, 26\% had 301-650 \$ monthly, and $13.1 \%$ had 651 and above (Table 1).

\section{Traumatic events experienced}

5.1.1. Types of traumatic events: Palestinians experiences variety of traumatic events: $98.1 \%$ reported hearing of shelling and bombardment of the area, $98.1 \%$ reporting hearing the sound of jetfighters, $96.4 \%$ reported watching mutilated bodies in TV, $94.2 \%$ reported saw the bombardment effect on ground, $73 / 1 \%$ said they left home form more safe place, $21.2 \%$ exposed to burn by bombs, and $5.8 \%$ had been arrested during incursions (Figure 1).

Palestinians experiences variety of traumatic events, the traumatic events ranged from one to 30 , total number of traumatic events experienced by each participants were 13.8 traumatic events $(\mathrm{SD}=6.1)$. The results showed that mean traumatic events reported by males was 13.92 ( $\mathrm{SD}=6.28)$ compared to mean in female=13.71 $(\mathrm{SD}=6.04)$. No significant differences between males and females in reporting traumatic events $(t=0.32)$. Correlation test was don the results showed that total traumatic events were correlated with total PTSD scores $(\mathrm{r}=0.08, \mathrm{p}=0.01)$.

Safety of families: The results showed that no one felt safe at home, $2.1 \%$ of fathers said they were able to protect their children, while $2.8 \%$ of mothers said they were safe at homes. The study showed that $3.1 \%$ fathers were able to protect their children compared to $6.6 \%$ of mothers, $2.8 \%$ of fathers were able to protect themselves compared to $6.1 \%$ of mothers, and $3.1 \%$ of fathers said that someone outside the home were able to protect him compared to $2.8 \%$ of mothers.

Loss of family members: The study showed that 71 persons lost someone from their family included extended family which represented
$18.8 \%$ of the participants and 303 did not loss anyone (81.2\%) from their families (first, second, third relatives) during the war.

Grief symptoms: The results showed that (61.1\%) were enjoying good memories of lost person, $45.8 \%$ feel that, even though he/she is gone, he/she is still an important part of his life, $40.3 \%$ can't stop thinking about the person who died when I want to think about other things, and $34.7 \%$ think about getting revenge on whoever is responsible for his/her death (Figure 2).

\begin{tabular}{|c|c|c|}
\hline & $\mathrm{N}$ & $\%$ \\
\hline \multicolumn{3}{|l|}{ 1. Sex } \\
\hline Male & 193 & 51.6 \\
\hline Female & 181 & 48.4 \\
\hline \multicolumn{3}{|c|}{ Mean $=41.53(\mathrm{SD}=7.48)$} \\
\hline \multicolumn{3}{|c|}{ 2. Place of residence } \\
\hline North Gaza & 128 & 34.2 \\
\hline Gaza & 93 & 24.9 \\
\hline Middle area & 59 & 15.8 \\
\hline Khan Younis & 29 & 7.8 \\
\hline Rafah area & 65 & 17.4 \\
\hline \multicolumn{3}{|l|}{ 3. Type of residence } \\
\hline City & 166 & 44.4 \\
\hline Village & 78 & 20.9 \\
\hline Camp & 130 & 34.8 \\
\hline \multicolumn{3}{|l|}{ 4. Education } \\
\hline Preparatory & 52 & 13.9 \\
\hline Primary & 96 & 25.7 \\
\hline Secondary & 141 & 37.7 \\
\hline University & 52 & 13.9 \\
\hline Postgraduate & 33 & 8.8 \\
\hline \multicolumn{3}{|l|}{ 5. Job } \\
\hline Unemployed & 76 & 20.3 \\
\hline Simple worker & 34 & 9.1 \\
\hline Skilled worker & 36 & 9.6 \\
\hline Employee & 64 & 17.1 \\
\hline Merchant & 9 & 2.4 \\
\hline Housewives & 155 & 41.4 \\
\hline \multicolumn{3}{|c|}{ 6. Family monthly income } \\
\hline Less than 300 US $\$$ & 190 & 60.9 \\
\hline $301-650 \$$ & 81 & 26.0 \\
\hline $651 \$$ and more & 41 & 13.1 \\
\hline
\end{tabular}

Table 1: Sociodemographic characteristics of study population $(N=374)$.

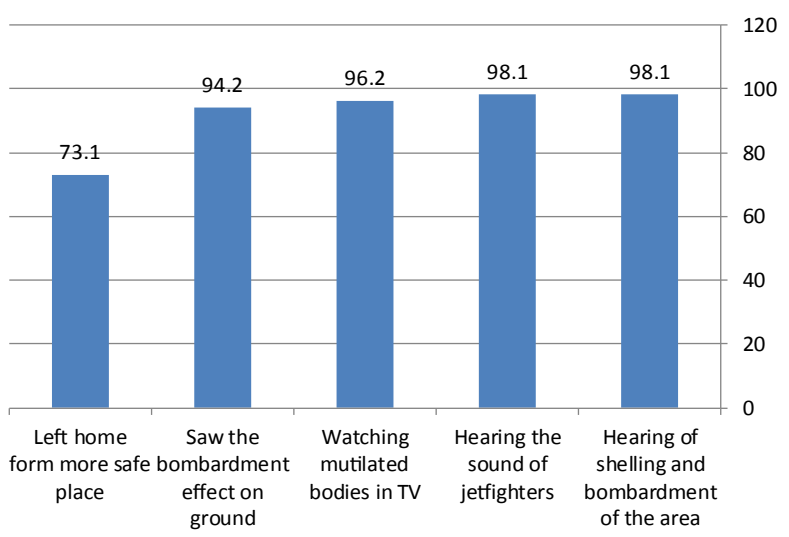

Figure 1: The most common traumatic events due to War on Gaza $(\mathrm{N}=374)$. 
Citation: Thabet AA, Tawahina AA, Sarraj EE, Vostanis P (2013) Death Anxiety, PTSD, Trauma, Grief, and Mental Health of Palestinians Victims of War on Gaza. Health Care Current Reviews 1: 112. doi: 10.4172/2375-4273.1000112

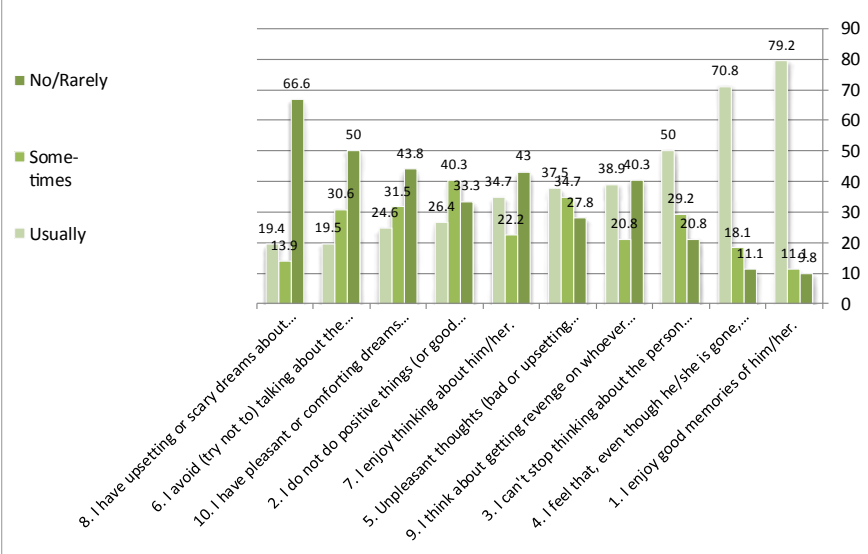

Figure 2: Grief Inventory items for lose people ( $N=71)$.

The study showed that mean grief reaction was $11.52(\mathrm{SD}=4.82)$. $\mathrm{T}$ independent test was done to find differences in grief reaction and sex of the participants. The study showed that mean grief reactions reported by male was $10.1(\mathrm{SD}=5.19)$ and mean in female was $12.69(\mathrm{SD}=4.19)$. There was statistically significant differences toward females in grief reactions $(\mathrm{t}=-2.12, \mathrm{p}=0.03)$.

In order to find the correlation between trauma and grief, Pearson coefficient correlation test was performed between total grief items and total traumatic events. The results showed no statistically significant correlation between trauma and grief $(\mathrm{r}=0.11, \mathrm{p}=0.32)$.

Determinants of grief scores and traumatic events: In order to find out the predictive effect of traumatic events on psychological symptoms, total grief symptoms was entered as dependent variable in a multiple regression model, with traumatic events as the independent variables. The results showed that the total grief scores was negatively associated with shooting by bullets, rocket, or bombs $(B=-29, p<0.007)$, and positively associated with, threaten by shooting $(B=.23, p<0.03)$, hearing shelling of the area by artillery $(B=.28, \mathrm{p}<0.01)$, and witnessing killing of a close relative $(\mathrm{B}=.22, \mathrm{p}<0.04)$ (Table 2$)$.

\section{Psychological reactions according to PTSD scale}

PTSD symptoms: The study showed that $50.5 \%$ had painful images or memories of the events, $48.7 \%$ of their thoughts of the events were reoccurring, $43.6 \%$ were upset by some things which reminded them of the events, and $32.9 \%$ had difficulty enjoying things (Figure 3 ).

Prevalence of PTSD and subscales: The mean PTSD-17 in males was 53.03 ( $\mathrm{SD}=13.35$ ) compared to mean scores in females $=56.62$ ( $\mathrm{SD}=11.89) \quad(\mathrm{t}$-test $=-3.6$, p-value $<0.01$ (., Reexperiences mean on males was $17.65(\mathrm{SD}=4.57)$ compared to $18.99(\mathrm{SD}=3.61)$ in females (t-test $=-3.15$, p-value $<0.01$ (., avoidance mean scores in males was $19.99(\mathrm{SD}=6)$ compared to $21.05(\mathrm{SD}=5.64)$ in females $(\mathrm{t}$-test=-1.75, p-value $<0.08$ (., Hyperarousal mean scores in males was 15.38 $(\mathrm{SD}=4.89)$ compared to $16.58(\mathrm{SD}=4.68)$ in females $(\mathrm{t}$-test $=-2.42$, $\mathrm{p}$-value $<0.02$ (.Using $\mathrm{T}$ independent test showed that females were diagnosed probably with PTSD more than males.

Prevalence of PTSD: Using scoring of DSM-IV of one reexperiences symptom, three avoidance, and two arousal symptoms, 248 people rated as PTSD which represented $66.6 \%$ of the sample and 125 persons reported no PTSD (35.5\%). The results showed that PTSD was reported more in females compared to males ( $74.6 \%$ vs. $58.9 \%)$. This rate reached statistically significant level $(X 2=\mathrm{df}=2, \mathrm{p}<0.001)$.
In order to find the correlation between total PTSD and grief reactions, Pearson coefficient correlation test was performed between total grief items and total PTSD. The results showed there were statistically significant correlations between grief and total PTSD $(\mathrm{r}=0.37, \mathrm{p}=0.01)$, intrusion symptoms $(\mathrm{r}=0.25, \mathrm{p}=0.01)$, avoidance $(\mathrm{r}=0.38, \mathrm{p}=0.01)$, and hyperarousal $(\mathrm{r}=0.29, \mathrm{p}=0.01)$.

Determinants of PTSD scores and traumatic events: In order to find out the predictive effect of traumatic events on PTSD symptoms, total PTSD symptoms was entered as dependent variable in a multiple regression model, with each traumatic event as the independent variables. The results showed that the total PTSD scores were positively associated with the following trauma items: threaten by shooting $(B=$ $.17, \mathrm{p}<0.001)$, deprivation from water or electricity during the war $(\mathrm{B}=.14, \mathrm{p}<0.005)$, and witnessing assassination of people by rocket $(\mathrm{B}=.14, \mathrm{p}<0.007)$. However threatened to death by being used as human shield to arrest your neighbors by the army was negatively predicted the PTSD $(\mathrm{B}=-.22, \mathrm{p}<0.001)($ Table 3$)$.

\section{Death anxiety}

The results showed that $59.5 \%$ said they had fears of the punishment in their grave, $51.9 \%$ said they had fears of having cancer, $50.5 \%$ said they are worried that death will take someone they love. While the least common items were: Walking in cemetery frightening them (11\%), upset when seeing funnel $(10.4 \%)$, and afraid visiting the cemetery (9.1\%) (Figure 4)

Sex differences in death anxiety: In order to find the differences between males and females in death anxiety, $\mathrm{T}$ independent test was done. The results showed that mean death anxiety in males was 37.4 $(\mathrm{SD}=20)$ compared to female mean $=44.9(\mathrm{SD}=18.5)$. There were

\begin{tabular}{|l|l|l|l|l|l|}
\hline & \multicolumn{2}{|l|}{$\begin{array}{l}\text { Unstandardized } \\
\text { Coefficients }\end{array}$} & $\begin{array}{l}\text { Standardized } \\
\text { Coefficients }\end{array}$ & & \\
\hline & B & Std. Error & Beta & t & Sig. \\
\hline (Constant) & 1.997 & 3.353 & & .596 & .553 \\
\hline $\begin{array}{l}\text { 17. Shooting by bullets, } \\
\text { rocket, or bombs }\end{array}$ & -3.939 & 1.425 & -.297 & -2.764 & .007 \\
\hline $\begin{array}{l}\text { 22. Threaten by shooting } \\
\text { 3. Hearing shelling of the }\end{array}$ & 2.260 & 1.062 & .235 & 2.129 & .037 \\
\hline $\begin{array}{l}\text { area by artillery } \\
\text { 7. Witnessing killing of a } \\
\text { close relative }\end{array}$ & 2.253 & 3.175 & .285 & 2.599 & .012 \\
\hline
\end{tabular}

$F=5.9, p<0.05, R^{2}=0.26$

Table 2: Linear Regression analysis of grief and traumatic events Coefficients(a).

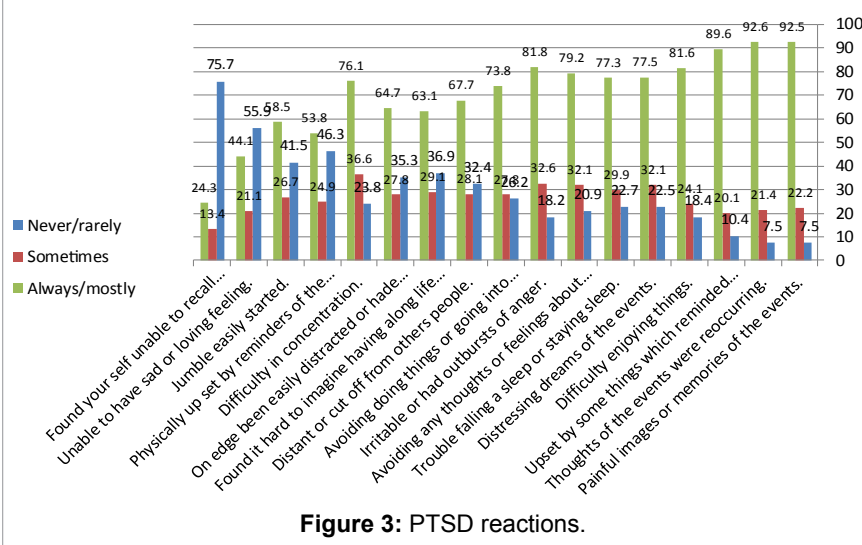

Figure 3: PTSD reactions 
Citation: Thabet AA, Tawahina AA, Sarraj EE, Vostanis P (2013) Death Anxiety, PTSD, Trauma, Grief, and Mental Health of Palestinians Victims of War on Gaza. Health Care Current Reviews 1: 112. doi: 10.4172/2375-4273.1000112

statistically significant differences toward females $(\mathrm{t}$-test $=-3.82, \mathrm{t}=$ $-3.82, \mathrm{p}=0.001)$.

In order to find the correlation between total death anxiety and grief reactions, Pearson coefficient correlation test was performed between total grief items and total death anxiety. The results showed there were no statistically significant correlations between grief and total death anxiety $(\mathrm{r}=0.11, \mathrm{p}=0.19)$.

Determinants of death anxiety and traumatic events: In order to find out the predictive effect of traumatic events on death anxiety symptoms, total death anxiety symptoms was entered as dependent variable in a multiple regression model, with each traumatic event as the independent variables. The results showed that the total death anxiety scores were positively associated with the following trauma items: forced to leave your home during the war $(B=.10, p<0.001)$, destroying of your personal belongings during incursion $(B=.13, p<0.01)$, Hearing the sonic sounds of the jetfighters $(B=.11, \mathrm{p}<0.02)$, deprivation from going to toilet and leave the room at home where you was detained $(\mathrm{B}=$ $.11, \mathrm{p}<0.04)$, and negatively associated with witnessing killing of a close relative $(\mathrm{B}=-.20 \mathrm{p}<0.04)$ (Table 4$)$.

\section{General mental health problems}

The Palestinians reported different psychological symptoms, the most common symptom was found everything getting on top of them (42.8\%), $29.7 \%$ felt that life is entirely hopeless, $29.7 \%$ thought of the possibility that you might make away with themselves, $28.3 \%$ felt constantly under strain, $27.5 \%$ found at times you couldn't do anything because their nerves were too bad (Figure 5).

The study showed than mean GHQ-28 was $15.6(\mathrm{SD}=7.1)$, somatization mean was $4.3(\mathrm{SD}=2.3)$, anxiety mean was $5(\mathrm{SD}=2.1)$,

\begin{tabular}{|c|c|c|c|c|c|}
\hline & \multicolumn{2}{|c|}{$\begin{array}{l}\text { Unstandardized } \\
\text { Coefficients }\end{array}$} & \multirow{2}{*}{$\begin{array}{l}\text { Standardized } \\
\text { Coefficients } \\
\text { Beta } \\
\end{array}$} & \multirow[t]{2}{*}{$\mathrm{t}$} & \multirow[t]{2}{*}{ Sig. } \\
\hline & B & Std. Error & & & \\
\hline (Constant) & 48.611 & 1.380 & & 35.233 & .000 \\
\hline 22. Threaten by shooting & 4.503 & 1.404 & .176 & 3.207 & .001 \\
\hline $\begin{array}{l}\text { 26. Threatened to death by } \\
\text { being used as human shield } \\
\text { to arrest your neighbours by } \\
\text { the army }\end{array}$ & -8.455 & 1.968 & -.222 & -4.296 & .000 \\
\hline $\begin{array}{l}\text { 21. Deprivation from water or } \\
\text { electricity during the war }\end{array}$ & 4.118 & 1.465 & .145 & 2.810 & .005 \\
\hline $\begin{array}{l}\text { 15. Witnessing assassination } \\
\text { of people by rockets }\end{array}$ & 3.641 & 1.354 & .140 & 2.689 & .007 \\
\hline
\end{tabular}

$F=15.18, p<0.05, R^{2}=0.18$

Table 3: Linear Regression analysis of PTSD and traumatic events.

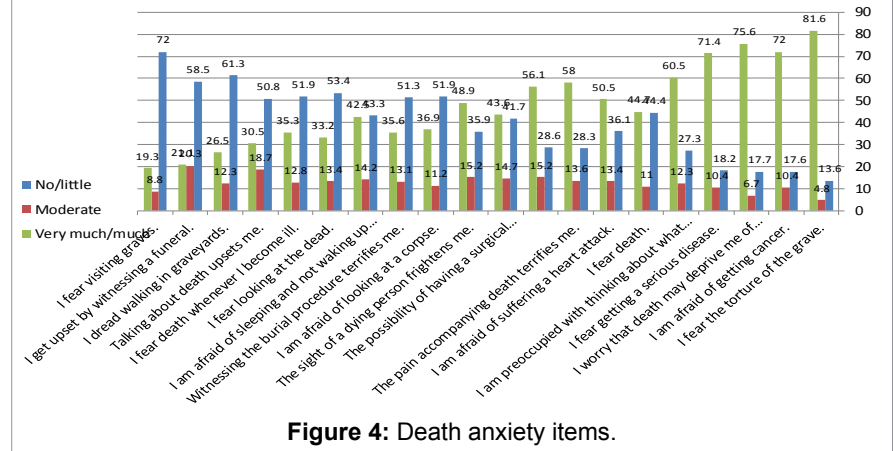

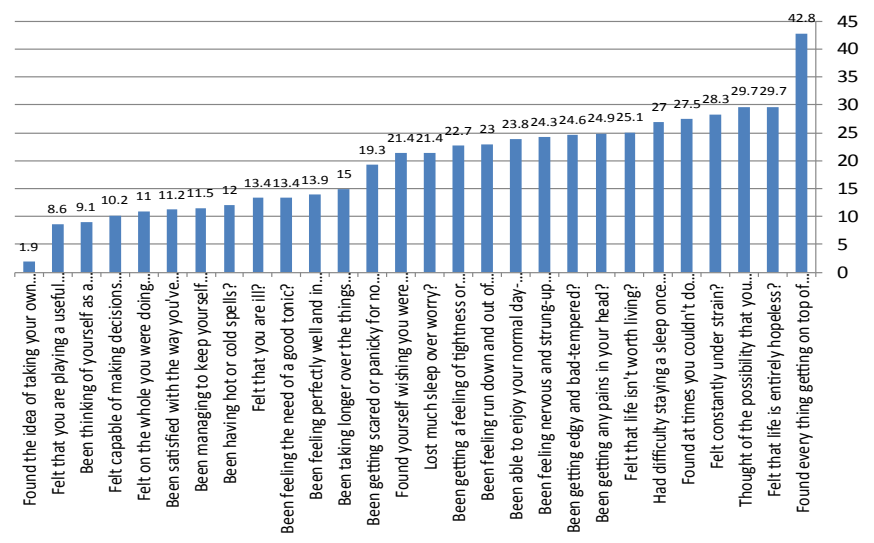

Figure 5: GHQ-28 items.

social dysfunction mean was $3.2(\mathrm{SD}=2.3)$, and depression mean was 3.2 ( $\mathrm{SD}=2.1$ ). Using the previous cutoff point of the GHQ-28 (4/5), the result showed that $90.9 \%$ were rated as cases and need further investigation, while $9.1 \%$ were not cases.

Determinants of GHQ-28 scores and traumatic events: In order to find out the predictive effect of traumatic events on general mental health symptoms, total GHQ-28 symptoms was entered as dependent variable in a multiple regression model, with each traumatic event as the independent variables. The results showed that the total GHQ scores were positively associated with the following items: destroying of your personal belongings during incursion $(B=.15, \mathrm{p}<0.003)$, Hearing shelling of the area by artillery $(B=.11, p<0.03)$, witnessing assassination of people by rocket $(B=.13, \mathrm{p}<0.01)$ and shooting by bullets, rocket, or bombs was negatively predicting mental health $(B=-$ $0.13, \mathrm{p}<0.01$ ) (Table 5).

\section{Discussion}

This study showed that Palestinians exposed to variety of traumatic events during the War on Gaza. Each one experienced around 12 traumatic events ranged from directed exposure to TV scenes, injury, shelling, and beating to indirect exposure by hearing about the death and bombardment of other areas in the Gaza Strip. The prevalence of PTSD was $66.6 \%$. These results consistent with previous research in the area Thabet et al. [5] in study of 200 families from North Gaza and East Gaza found that each parent reported a mean number of 8.5 traumatic events and $60 \%$ of parents had symptoms of potential clinical significance of PTSD, and 26.0\% reported severe to very severe anxiety symptoms. Also, Thabet et al. [8] in a study aimed to investigate the effect of political violence on 420 adult Palestinians in the Gaza Strip. The study population included living in the Gaza Strip, found that most common traumatic events were, watching mutilated bodies and wounded people on TV (97.1\%), hearing the sonic sounds of the jetfighters (94.7\%), and witnessing the signs of shelling on the ground (93.2\%). Participants reported a mean number of 7.7 traumatic events and $54.4 \%$ had symptoms of potential clinical significance of PTSD.

Our study showed that $61.1 \%$ of the people who lost someone close were enjoying good memories of lost person, $45.8 \%$ feel that, even though he/she is gone, he/she is still an important part of his life, $40.3 \%$ can't stop thinking about the person who died when I want to think about other things, and $34.7 \%$ think about getting revenge on whoever is responsible for his/her death. Those findings congruent 
Citation: Thabet AA, Tawahina AA, Sarraj EE, Vostanis P (2013) Death Anxiety, PTSD, Trauma, Grief, and Mental Health of Palestinians Victims of War on Gaza. Health Care Current Reviews 1: 112. doi: 10.4172/2375-4273.1000112

Page 7 of 8

\begin{tabular}{|c|c|c|c|c|c|}
\hline & \multicolumn{2}{|c|}{ Unstandardized Coefficients } & \multirow{2}{*}{$\begin{array}{c}\text { Standardized Coefficients } \\
\text { Beta }\end{array}$} & \multirow[t]{2}{*}{$\mathrm{t}$} & \multirow[t]{2}{*}{ Sig. } \\
\hline & B & Std. Error & & & \\
\hline (Constant) & 27.569 & 4.694 & & 5.873 & .000 \\
\hline 30. Forced to leave your home during the war & 4.472 & 2.269 & .102 & 1.971 & .049 \\
\hline 7. Witnessing killing of a close relative & -8.885 & 2.370 & -.201 & -3.749 & .000 \\
\hline 23. Destroying of your personal belongings during incursion & 5.362 & 2.245 & .133 & 2.389 & .017 \\
\hline 4. Hearing the sonic sounds of the jetfighters & 9.807 & 4.385 & .112 & 2.237 & .026 \\
\hline 27. Deprivation from going to toilet and leave the room at home where you was detained & 5.200 & 2.566 & .114 & 2.027 & .043 \\
\hline
\end{tabular}

$F=7.26, p<0.05, R^{2}=0.09$

Table 4: Linear Regression analysis of Death anxiety and traumatic events

\begin{tabular}{|c|c|c|c|c|c|}
\hline & \multicolumn{2}{|c|}{ Unstandardized Coefficients } & \multirow{2}{*}{$\begin{array}{c}\text { Standardized Coefficients } \\
\text { Beta }\end{array}$} & \multirow[t]{2}{*}{$\mathrm{t}$} & \multirow[t]{2}{*}{ Sig. } \\
\hline & B & Std. Error & & & \\
\hline (Constant) & 10.236 & 1.886 & & 5.427 & .0001 \\
\hline 23. Destroying of your personal belongings during incursion & 2.296 & .764 & .158 & 3.005 & .003 \\
\hline 3. Hearing shelling of the area by artillery & 3.936 & 1.816 & .112 & 2.167 & .031 \\
\hline 15. Witnessing assassination of people by rockets & 1.887 & .757 & .130 & 2.493 & .013 \\
\hline 17. Shooting by bullets, rocket, or bombs & -2.454 & 1.018 & -.130 & -2.410 & .016 \\
\hline
\end{tabular}

$F=6.26, p<0.05, R^{2}=0.06$

Table 5: Linear Regression analysis of general health and traumatic events.

with cultural norms of considering the dead person during war will be as martyr and will go to heaven and lost here is not permanent and that the dead person is alive in heaven and looking to their action in the daily life. Our study showed that females had more grief scores than males and also women reported more death anxiety symptoms than men, among possible explanations for the gender effect is simply that men were less willing to admit openly to their fears. Women may be "closer to their feelings" than men [16]. Kastenbaum also suggested that the greater concern about death reported by women may stem from the fact that they are most often the primary caretakers for the dying. Another explanation for gender differences in death anxiety invokes the concept of locus of control. Sadowski et al. [18] measured death anxiety along with locus of control and found that women were both more concerned about death and more externally controlled. Our results consisted with Abdel-Khalek [19] study of Egyptian normal participants (non-clinical), anxiety disorder patients, and patients suffering from schizophrenia, and addicts found gender differences were statistically significant on the Arabic Version of Death Anxiety in which females attained higher mean scores than their male counterparts in the three categories-normal participants (non-clinical), anxiety disorder patients, and patients suffering from schizophrenia-as well as the total group of males versus females. Our finding is congruent with previous results [20-23] and manifested strongly in Arab samples $[14,24]$. Our study is also consistent with study that aims to explore various psychosocial correlates associated with how Chinese react to death and dying of 282 Chinese college students Results showed that younger as compared with older participants and women as compared with men tended to be more death anxious. Those with low levels of self-efficacy and external health control orientations were more likely to report a high level of death anxiety.

The study showed than mean GHQ-28 was 15.6 , somatization mean was 4.3 , anxiety mean was 5 , social dysfunction mean was 3.2 , and depression mean was 3.2. Using the previous cutoff point of the GHQ-28 (4/5), the result showed that $90.9 \%$ were rated as cases and need further investigation, while $9.1 \%$ were not cases. Our mean mental health problems rated by GHQ was higher than the mean mental health problems rated by the same instrument, Cardozo et al. [3] in study of prevalence of psychiatric morbidity associated with the war in Kosovo, Estimated mean total score based on a possible GHQ28 questions was 11.1. Although we found that the GHQ-28 was well accepted and easy to administer, the interpretation of the results for prevalence estimates is not straightforward unless an optimal cutoff score is established for the specific population. Goldberg et al. [25] have suggested that a mean score will provide a rough guide to the best threshold; however, this would always result in a general psychiatric morbidity prevalence of approximately $50 \%$. Also the results of this study was consistent with previous study validity of this instrument in Arab culture in which the mean GHQ-28 for the referred cases for community mental health centers was 14.9 compared to only 8.3 of the controls [7]. This study results were higher than the rate of psychiatric caseseness found in study of survivor of the Piper Alpha oil platform disaster which took place on 6 July 1988, resulting in the deaths of 167 men and leaving 59 survivors. It involved the complete destruction above sea level of the platform at $193 \mathrm{~km}$ northeast of Aberdeen, a city in the Grampian region of Scotland. The study showed that after 10 years $44 \%$ of the traced survivors (16/36) scored above 4 in GHQ-28 [26]. This study showed that the best predictive traumatic events for mental health problems were destroying of your personal belongings during incursion, hearing shelling of the area by artillery, witnessing assassination of people by rocket, while shooting by bullets, rocket, or bombs was negatively predicting mental health. This combination of direct and indirect traumatic events predication of mental health problems denoting that not only trauma may lead to mental health problems but, there may be other contributing factors which increase the risk for mental health problems in Palestinians living in area of war and conflict such as siege, unemployment, increase family members, and overcrowdings.

\section{Conclusions}

This study revealed that adult's victims of last War on Gaza and living in area of conflict and war for long time are exposed to different traumatic events ranging from indirect to indirect trauma, the most common reported traumatic events were hearing of shelling and bombardment of the their area, watching mutilated bodies in TV, seeing the bombardment effects on ground, lack of water, food and electricity during the war, and moving to save place during the war. Each person 
Citation: Thabet AA, Tawahina AA, Sarraj EE, Vostanis P (2013) Death Anxiety, PTSD, Trauma, Grief, and Mental Health of Palestinians Victims of War on Gaza. Health Care Current Reviews 1: 112. doi: 10.4172/2375-4273.1000112

reported 13.80 traumatic events. The results showed that no one felt safe at home. The study showed that 71 persons lost someone from their family included extended family which resulted in grief reaction where females reported more grief reactions. PTSD rate was $66.6 \%$ of the sample PTSD was reported more in females compared to males. The results showed that death anxiety was more in females. For general mental health problems, $91 \%$ were rated as cases and need further investigation. Such findings highlight the impact of war on civilian and especially those who lost someone in the family. Those victims had to be evaluated and treated as soon as the war finished and not leaving them to develop pathological grief and other mental health problems such as depression. Training programs must be created for people living in area of war and conflict including community sessions to increase their awareness about the impact of war on their psychosocial health and ways of coping with such problems in similar situation. Also, new intervention programs must be established for bereaved people using individual psychotherapy, psychoeducation, group crisis intervention, and community based intervention.

International organizations and national organization must work during war to protect civilian people from the atrocities of the war and provided a safe place for people and their children.

\section{References}

1. de Jong JT, Komproe IH, Van Ommeren M, El Masri M, Araya M, et al. (2001) Lifetime events and posttraumatic stress disorder in 4 post conflict settings. JAMA 286: 555-562.

2. Cardozo BL, Kaiser R, Gotway CA, Agani F (2003) Mental health, socia functioning, and feelings of hatred and revenge of Kosovar Albanians one year after the war in Kosovo. J Trauma Stress 16: 351-360.

3. Cardozo BL, Vergara A, Agani F, Gotway CA (2000) Mental health, social functioning, and attitudes of Kosovar Albanians following the War in Kosovo. JAMA 284: 569-577.

4. Rosner R, Powell S, Butollo W (2003) Post traumatic stress disorder three years after the siege of Sarajevo. J Clin Psychol 59: 41-55.

5. Thabet AA, Tawahina AA, Eyad EL, Panos V (2008a) Exposure to war trauma and PTSD among parents and children in the Gaza strip. Eur Child Adolesc Psychiatry 17: 191-199.

6. Thabet AA, Abu Tawahina A, El Sarraj E, Vostanis P (2008b), "The Relationship Between Siege Of Gaza Strip, Anger, And Psychological Symptoms, Arabpsynet E Journal 20: 174-184.

7. Thabet AA, Vostanis $P(2005)$ The Validity and Reliability of Arabic Version of General Health Questionnaire in the Gaza Strip. Palestinian Medical Journal 1: 33-36.
8. Thabet AA, Abu Tawahina A, El Sarraj E, Vostanis P (2009) Effect of political violence on Palestinians in the Gaza Strip. Arabpsynet $E$ Journal.

9. Kastenbaum R (1987) Death-related anxiety. Anxiety and stress disorders: Cognitive-behavioral assessment and treatment. Guilford Press, New York.

10. Abdel-Khalek AM (2004b) Death anxiety, death depression, and death obsession: A general factor for death distress is evident: A reply. Psychol Rep 94: 1212-1214.

11. Abdel-Khalek AM, Abdulla T (2006) Death Obsession in Palestinians. Death Stud 30: 203-215.

12. Abdel-Khalek AM (1998) The structure and measurement of death obsession Personality and Individual Differences 24: 159-165.

13. Abdel Khalek AM, Saleh G (1999) Death concern: A comparative study on Syrian samples. Derasat Nafseyah 9: 177-189.

14. Abdel Khalek AM (2003) Death anxiety in Spain and five Arab countries. Psychol Rep 93: 527-528.

15. Pollack JM (1980) Correlates of death anxiety: A review of empirical studies Omega 10: 97-121.

16. Kastenbaum R (2000) The psychology of death. (3rdedn), Springer Publishing Company, New York.

17. Lonetto R, Mercer GW, Fleming S, Bunting B, Clare M (1980) Death anxiety among university students in Northern Ireland and Canada. J Psychol 104 $75-82$.

18. Sadowski CJ, Davis SF, Loftus-Vergari MC (1979) Locus of control and death anxiety: A reexamination. Omega 10: 203-210.

19. Abdel-Khalek AM (2005) Death anxiety in clinical and non-clinical group. Death Stud 29: 251-259.

20. Abdel-Khalek AM (2002a) Death, anxiety, and depression: A comparison between Egyptian, Kuwaiti, and Lebanese undergraduates. Omega: Journal of Death and Dying 45: 277-287.

21. Abdel-Khalek AM (2002b) Death obsession in Egyptian samples: Differences among people with anxiety disorders, schizophrenia, addictions, and normal. Death Stud 26: 413-424.

22. Dattel AR, Neimeyer RA (1990) Sex-differences in death anxiety: Testing the emotional expressiveness hypothesis. Death Stud 14: 1-11.

23. Kastenbaum R (1992) The psychology of death. (2ndedn), Springer, New York

24. Abdel-Khalek AM (1986) Death anxiety in Egyptian samples. Personality and Individual Differences 7: 479-483.

25. Goldberg DP, Oldehinkel T, Ormel J (1998) Why GHQ threshold varies from one place to another. Psychol Med 28: 915-921.

26. Hull A, Alexander D, Klein S (2002) Survivors of the Piper Alpha oil platform disaster: long-term follow-up study. Br J Psychiatry 181: 433-438. 